\title{
OPTIMIZATION VIA SIMULATION FOR INVENTORY CONTROL POLICIES AND SUPPLIER SELECTION
}

\author{
Gocken, M.; Dosdogru, A. T. \& Boru, A. \\ Engineering and Natural Sciences Faculty, Department of Industrial Engineering, \\ Adana Science and Technology University, 01180, Adana, Turkey \\ E-Mail: mgocken@adanabtu.edu.tr, adosdogru@adanabtu.edu.tr, aboru@adanabtu.edu.tr
}

\begin{abstract}
The need to explicitly select the best review model in inventory control system is greater than ever because managing and controlling inventories are difficult under intense competition. In this study, three important questions are answered in inventory control system: which review model (periodic or continuous) should be used; which objective function of review model should be used to increase competitiveness of the supply chain; how to find the optimal values of initial inventory, reorder point, and order-up-to level for each Distribution Centre (DC) and each Supplier. We proposed an Optimization via Simulation (OvS) approach to determine the best inventory control system with supplier selection and to obtain a remarkable amount of saving while increasing the competitive edge in a fully stochastic supply chain environment. According to the results, total supply chain cost can be improved at least $22 \%$ and at most $66 \%$ on average with proposed continuous review model.

(Received in August 2016, accepted in January 2017. This paper was with the authors 2 months for 2 revisions.)
\end{abstract}

Key Words: Inventory Control System, $(s, S)$ Policies, Optimization via Simulation

\section{INTRODUCTION}

To remain competitive, companies must provide high quality, high responsiveness, and low cost. So they should know that managing supply chain members plays a key role to organize supply chain effectively. In this case, the determination of the correct review model to be used in supply chain members becomes inevitable so as to achieve company's goals. In literature, two basic types of review models: a continuous review model and a periodic review model are used. But there has always been a confusion on which review model will be the best and what should be the values of the parameters for each model. This study fulfils a part of this gap by studying periodic $(s, S)$ and continuous $(s, S)$ policies in a fully stochastic two echelon supply chain with lost sales. After scanning the literature, we determined that there is a number of studies performed to analyse $(s, S)$ policies. For example, the optimality of $(s, S)$ policy is proven assuming linear holding and stockout costs, and fixed ordering costs [1]. Hollier et al. [2] formed $(s, S)$ policy using mathematical model where products experience lumpy demand patterns and cutoff transaction size is incorporated into the policy. Bashyam and Fu [3] incorporated service level constraint and general random lead times in the determination of optimal settings of $(s, S)$. Moors and Strijbosch [4] derived an exact formula for the average stockout in a replenishment cycle of $(s, S)$ policy where stationary gamma demand process and deterministic lead time are used. $\mathrm{Hu}$ et al. [5] presented a multi-retailer system with centralised ordering in $(s, S)$ policy. Tlili et al. [6] proposed a two echelon inventory control system including an outside supplier, a warehouse and two retailers. In the study, $(s, S)$ policy is used to control inventory of the warehouse and retailers. Cabrera et al. [7] analysed the stochastic capacity constraint under $(s, S)$ policy that directly affects distribution network design. Nasr and Maddah [8] derived an equation to calculate the long run cost for a given ( $s$, $S)$ policy and also evaluated dynamic and static $(s, S)$ policies under Markov modulated Poisson process demand. Göçken et al. [9] utilized an OvS approach for simultaneous optimization of both parameters of the periodic $(s, S)$ policy and determination of the most suitable supplier for each DC in a fully stochastic two echelon supply chain by considering 
total supply chain cost $(T S C C)$. Note that periodic $(s, S)$ policy is also known as $(R, s, S)$ policy.

Whatever $(s, S)$ policy is used depends on the corresponding costs since different types of business objective are available in today's competitive marketplace. At this point, balancing the two underlying opposing risks, the risk of underordering incurring stockout cost, and the risk of overordering incurring holding costs can be considered as one of the most important objectives. Also, Levi et al. [10] presented that this objective works reasonably better than minimizing the sum of the two costs. However, total cost function per unit time which can be considered as a most common measure of effectiveness is generally used to determine the optimal $(s, S)$ policies [11]. Therefore, we present the critical decision of whether minimizing total supply chain cost over periods (Model 1) or minimizing differences between overordering cost and underordering cost (Model 2) while determining the optimal inventory control parameters (initial inventory, reorder point, and order-up-to level) that coordinate stock levels in DCs and Suppliers. Moreover, proper selection of the set of Suppliers for DCs is handled simultaneously. Our proposed OvS models provide a significant opportunity to find optimum inventory control systems. In addition, they give reasonable solutions for evaluating different configurations of inventory control system with supplier selection. Supplier selection based on OvS methodology can be found in Ding et al. [12] where Genetic Algorithm (GA) is used for supplier selection decisions and discrete-event model is used for operational performance evaluation. Note that developing robust models that have an ability to solve inventory control problem with supplier selection are very important in lost sales environment. Therefore, comprehensive researches are needed to better understand how the lost sales affect the total supply chain. Annadurai and Uthayakumar [13] used controllable lead time and illustrated the impacts of increasing logarithmic and power investments to decrease the lost sales rate. The lost sales rate, review period, and lead time are taken as decision variables and basic periodic review system is formulated mathematically with the capital investment. Bijvank and Johansen [14] compared lost sales inventory models with various replenishment systems. Also, closed-form expressions are derived to approximate the performance measures of interest for lost sales inventory control with the pure base-stock policies.

Our study serves the following purposes: (1) Create more flexible and responsive OvS models for inventory control systems; (2) Determine the optimal values of reorder point, order-up-to level, and initial inventory for each DC and each Supplier while properly selecting the set of Suppliers for DCs under lost sales system and stochastic environment; (3) Determine which review model is preferable when different companies' objectives are considered; (4) Provide comprehensive analysis on the important decision of whether minimizing TSCC over periods or minimizing differences between overordering cost and underordering cost for $(s, S)$ policies.

\section{PROBLEM DEFINITION}

Our supply chain consists of single product from Suppliers to DCs and DCs to customers along a chain. Inventory levels of DCs and Suppliers are all monitored considering continuous review $(s, S)$ policies and periodic review $(s, S)$ policies. They are used for three $\mathrm{DC}_{i}(i$ denotes DC in the system, $i=1, \ldots, I)$ and five $\operatorname{Supplier}_{j}(j$ denotes number of Suppliers in the system, $j=1, \ldots, J)$. Before proceeding with the proposed models, we summarize the used notation. $n$ is the set of periods where a period is one month, $n=1, \ldots, N) . X_{i n}$ and $X_{j n}$ are the inventory level of $\mathrm{DC}_{i}$ and Supplier ${ }_{j}$ at period $n$, respectively. $X_{i n}^{-}$and $X_{j n}^{-}$are the unmet customer order quantity of $\mathrm{DC}_{i}$ and Supplier ${ }_{j}$ over period $n$, respectively. $X_{i n}^{+}$and $X_{j n}^{+}$are the remaining inventory quantity of $\mathrm{DC}_{i}$ and Supplier $_{j}$ over period $n$, respectively. $h_{i}$ and $h_{j}$ are 
defined as the inventory holding cost rate of $\mathrm{DC}_{i}$ and Supplier ${ }_{j}$ for each unit of inventory, respectively. $k_{i}$ and $k_{j}$ are specified as the lost sales cost rate of $\mathrm{DC}_{i}$ and Supplier $_{j}$ for each unit of stockout, respectively. $p_{i}$ and $p_{j}$ are defined as the processing cost of $\mathrm{DC}_{i}$ and Supplier $_{j}$, respectively. $P_{i}$ and $P_{j}$ are the processing time of $\mathrm{DC}_{i}$ and Supplier $_{j}$, respectively. The order cost per use of $\mathrm{DC}_{i}$ and Supplier ${ }_{j}$ respectively are defined as $c_{i}$ and $c_{j}$ which are the cost charged for any order of $\mathrm{DC}_{i}$ and Supplier ${ }_{j}$ irrespective of the time spent in there. The order processing cost of $\mathrm{DC}_{i}$ and Supplier ${ }_{j}$ is denoted as respectively $O_{i}$ and $O_{j}$ that include order processing cost rate and cost per use. Order processing cost rate is proportional the order processing time. Cost per use is the one-time cost which is accrued each time any supply chain member is used. I\{.\} represents indicator function of the set. Two OvS models (Model 1 and Model 2) are created to determine the optimal inventory control policy parameters and to select the best supplier.

Model 1: TSCC over periods is calculated as follows:

$$
\begin{aligned}
\min T S C C=\sum_{n=1}^{\text {Periods Considered }} & \left\{\sum_{i=1}^{I} h_{i} X_{\text {in }}^{+}+\mathrm{I}\left\{X_{\text {in }} \leq \mathrm{s}\right\}\left(k_{i} X_{\text {in }}^{-}+p_{i} P_{i}+c_{i}+O_{i}\right)\right\}+ \\
& \left.\left\{\sum_{j=1}^{J} h_{j} X_{j n}^{+}+\mathrm{I}\left\{X_{j n} \leq \mathrm{s}\right\}\left(k_{j} X_{j n}^{-}+p_{j} P_{j}+c_{j}+O_{j}\right)\right\}\right)
\end{aligned}
$$

Model 2: The total difference cost function over periods (THL) is calculated as follows:

$$
\begin{aligned}
\min T H L=\sum_{n=1}^{\text {Periods Considered }} & \sum_{i=1}^{I}\left(h_{i} X_{i n}^{+}-\mathrm{I}\left\{X_{\text {in }} \leq \mathrm{s}\right\}\left(k_{i} X_{\text {in }}^{-}\right)\right)+\sum_{j=1}^{J}\left(h_{j} X_{j n}^{+}-\right. \\
& \left.\mathrm{I}\left\{X_{j n} \leq \mathrm{s}\right\}\left(k_{j} X_{j n}^{-}\right)\right)
\end{aligned}
$$

For OvS models, cost and replenishment lead time related parameter values are specified as seen in Table I.

Table I: The value of parameters for Suppliers and DCs.

\begin{tabular}{|l|l|}
\hline \multicolumn{1}{|c|}{ Suppliers } & \multicolumn{1}{c|}{ DCs } \\
\hline Average Holding Cost: Uniform $(2,5)$ & Average Holding Cost: Uniform $(2,5)$ \\
\hline Lost Sales Cost: Uniform $(80,100)$ & Lost Sales Cost: Uniform $(80,100)$ \\
\hline Processing Cost: Uniform $(50,75)$ & Processing Cost: Uniform $(5,10)$ \\
\hline Order Cost Per Use: Uniform $(50,100)$ & Order Cost Per Use: Uniform $(50,100)$ \\
\hline Order Processing Cost Rate: Uniform $(2,5)$ & Order Processing Cost Rate: Uniform $(2,5)$ \\
\hline Cost Per Use: Uniform $(100,150)$ & Cost Per Use: Uniform $(10,20)$ \\
\hline Processing Time: Triangular $(3,5,7)$ minutes & Processing Time: Triangular $(1,2,3)$ minutes \\
\hline Order Processing Time: Uniform $(2,5)$ hours & Order Processing Time: Uniform $(2,5)$ hours \\
\hline & Transportation Time: Uniform $(1.25,3)$ days \\
\hline
\end{tabular}

Continuous review: Inventory levels of each DC and each Supplier are all inspected using continuous $(s, S)$ policies. According to continuous $(s, S)$ policies in a lost sales environment whenever the inventory level declines below the reorder level $(s)$, an order is given to increase the inventory level of each DC and each Supplier until the order-up-to level $(S)$.

Periodic review: Inventory levels of each DC and each Supplier are all inspected at every $R$ time units where $R$ is a fixed constant and assumed to be 5 days. It should be noted that only this value is considered to be constant and assumed to be the same for all Suppliers and DCs placed. At the beginning of each review period, the inventory level of each DC and each Supplier is increased until the order-up-to level whenever it decreases to a value smaller than or equal to the reorder point. Note that the replenishment lead time of $\mathrm{DC}_{i}$ and Supplier ${ }_{j}$ should be smaller than review period. 
Continuous review and periodic review model: Each DC/Supplier has their own initial inventory, reorder point, and order-up-to level values separately. The distribution of the customer order quantity at the DCs has a Poisson distribution with a rate parameter of 50 . Also, we assumed that average customer arrival rate at each DC is 1 per day. The DC replenishment orders may vary depending on the order quantity between successive orders and the resulting inventory at the time of ordering. The replenishment lead time of each supply chain member is assumed to be stochastic. DCs' replenishment lead times include order processing time, transportation time from Suppliers to DCs, and processing time while Suppliers' replenishment lead times include order processing time and processing time. Note that processing time represents the time needed to prepare items for serving at each supply chain members. Order processing time signifies the length of time between the time when an item order is placed and when it is ready to satisfy DC/Supplier order.

\section{OPTIMIZATION VIA SIMULATION}

OvS provides a significant opportunity to solve supply chain problem because OvS has the ability of capturing the advantages of both simulation and optimization based methods simultaneously [15-16]. Basically, OvS problem can be formulated as a minimization problem:

$$
\min _{x \in X} J(x)
$$

where $x$ is a $p$-dimensional vector of all the solution variables and $X$ is the feasible solution space. The objective function $J$ cannot be obtained directly, but rather is an expectation of another quantity $L(x ; w)$, to which we have access by running stochastic simulations, i.e.,

$$
J(x)=E[L(x ; w)]
$$

where $w$ represents the stochasticity in the system. In our setting, a sample of $w$ represents a simulation run, and $L(x ; w)$ is a sample performance estimate obtained from the output of the simulation run. Multiple simulation runs should be performed to provide a good estimate of $E[L(x ; w)]$. Let $\widetilde{N}$ specifies the number of simulation runs and $w_{j}$ is the $j^{\text {th }}$ sample of the randomness $w$. Thus, $L\left(x ; w_{j}\right)$ is the performance estimate obtained from the output of the simulation run $j$. The standard approach is to estimate $E[L(x ; w)]$ by the sample mean performance measure.

$$
\bar{J}(x) \equiv \frac{1}{\widetilde{N}} \sum_{j=1}^{\widetilde{N}} L\left(x ; w_{j}\right)
$$

As $\widetilde{N}$ increases, $\bar{J}(x)$ becomes a better estimate of $E[L(x ; w)]$. Details about OvS models can be found in [17].

Basically, our OvS models include two fundamental tools: (1) An optimization tool (GA) is used to find the optimal result; (2) A simulation tool evaluates performances of candidate solutions. An excellent survey of the use of metaheuristics for OvS was presented by Ólafsson [18]. GA is one prominent example, but others such as simulated annealing, tabu search and many variations are available. In this study, GA is developed to assign new values for selected decision variables (i.e., generating candidate solutions). In each cycle, simulation output is returned to the GA as the most recent fitness function to be evaluated, and GA once more tries to find better decision variables values to increase model performance. The basic structure of GA can be found in [9]. In GA, selection, crossover and mutation are repeatedly applied to form new chromosomes. Note that in this study, not only TSCC but also THL are considered for the calculation of fitness value. Thus, fitness value $f_{k}$ is computed for chromosome $k$ by using the objective function value as given in Eq. (6):

$$
f_{k}=\frac{1}{T S C C \text { or } T H L}
$$


where TSCC or THL is the objective function value of the $k^{\text {th }}$ chromosome. The values of crossover rate, mutation rate, number of iteration, and population size are taken as $0.8,0.05$, 150,50 , respectively.

Simulation seems a remarkable recourse to model and analyse the performance for supply chain. The outcomes for different alternatives are evaluated via simulation and therefore, unnecessary errors and costs are minimized [19-21]. In this study, simulation models are created by using Simio (Version: 7.121.12363). Simio is a multi-paradigm modelling tool that incorporates all paradigms into a single framework [22].

Our simulation model assumptions are given as follows: (1) Two echelon supply chain consists of single product from Suppliers to DCs and DCs to customers; (2) Determined inventory control parameters remain the same across the entire finite time horizon; (3) Stochastic demand and stochastic lead time are used; (4) Single predetermined DC is used to satisfy each customer demand. Single Supplier that is assigned after the optimization phase is used to meet each DC replenishment order. Each Supplier replenishes its inventory from unlimited sources; (5) If the order quantity is higher than the current inventory level of supply chain member, possible order fulfilment takes place and unmet demand is lost; (6) Only transportation times between Suppliers and DCs are considered; (7) Simulation model is run for one year; (8) Inventory levels are not allowed to be negative.

\section{RESULTS AND DISCUSSION}

In this study, four OvS models have been proposed, each having its own advantages and disadvantages. P-Model 1 denotes periodic review model whose objective function is TSCC. P-Model 2 specifies periodic review model whose objective function is THL. C-Model 1 denotes continuous review model whose objective function is TSCC. C-Model 2 specifies continuous review model whose objective function is THL. The convergence results for OvS models are plotted in Fig. 1, where cost of P-Model 1 and C-Model 1 in the y axis includes the direct cost and indirect cost.
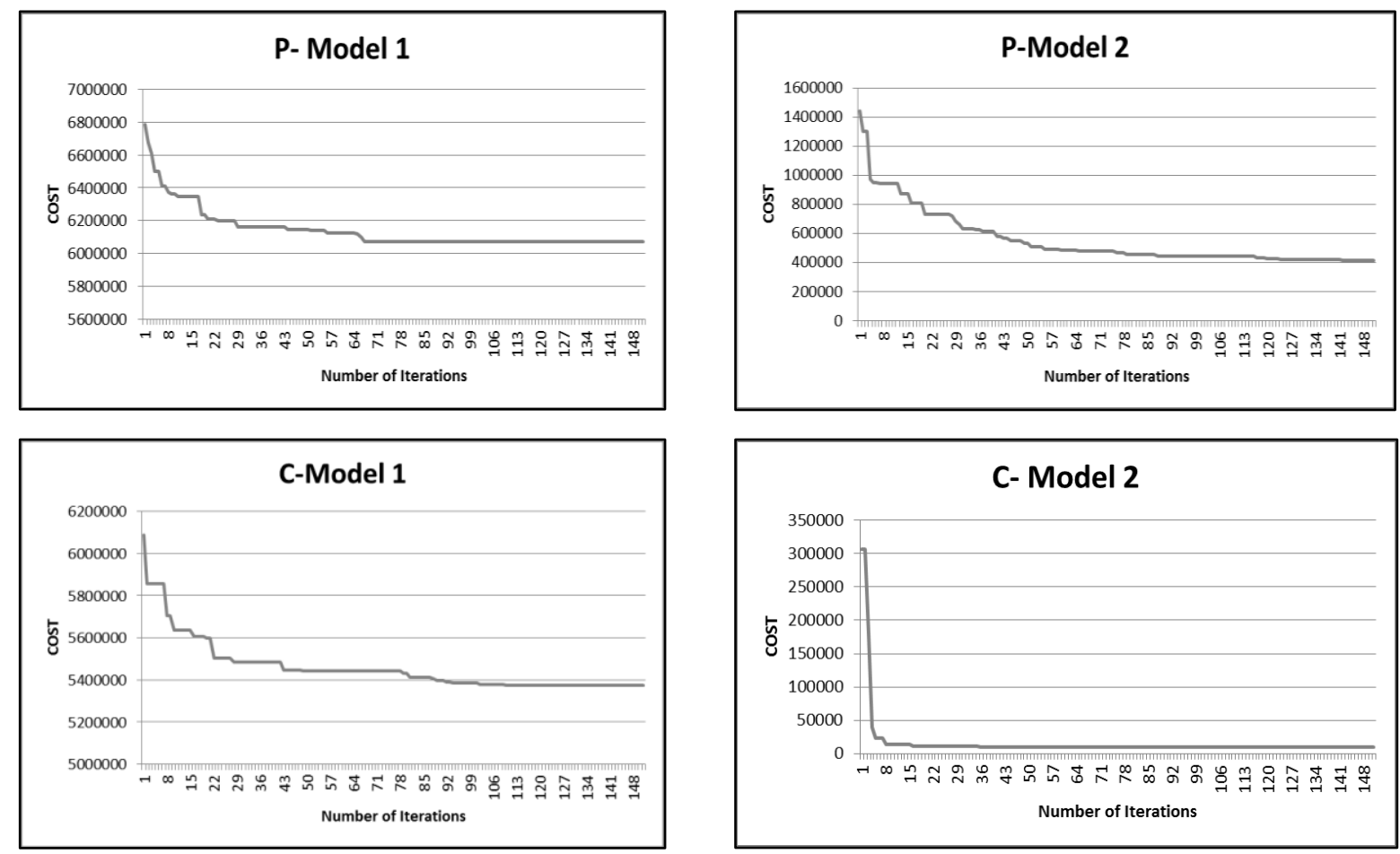

Figure 1: The convergence results for periodic review and continuous review policies. 
Table II: The optimal values of inventory control parameters.

\begin{tabular}{|c|c|c|c|c|}
\hline $\begin{array}{c}\text { Supply Chain } \\
\text { Member }\end{array}$ & Model Type & Initial Inventory & Reorder Point (s) & Order-up-to Level $(S)$ \\
\hline \multirow{4}{*}{ DC1 } & $\mathrm{P}^{*}$-Model 1 & 1897 & 82 & 656 \\
\hline & P-Model 2 & 1658 & 197 & 679 \\
\hline & $\mathrm{C}^{*}$-Model 1 & 1973 & 178 & 493 \\
\hline & C-Model 2 & 1197 & 113 & 552 \\
\hline \multirow{4}{*}{ DC2 } & P-Model 1 & 1897 & 82 & 503 \\
\hline & P-Model 2 & 1949 & 197 & 679 \\
\hline & C-Model 1 & 1973 & 178 & 493 \\
\hline & C-Model 2 & 1677 & 166 & 552 \\
\hline \multirow{4}{*}{ DC3 } & P-Model 1 & 1985 & 82 & 503 \\
\hline & P-Model 2 & 1949 & 197 & 679 \\
\hline & C-Model 1 & 1973 & 175 & 493 \\
\hline & C-Model 2 & 1311 & 166 & 434 \\
\hline \multirow{3}{*}{ Supplier1 } & P-Model 2 & 1949 & 197 & 679 \\
\hline & C-Model 1 & 1160 & 175 & 448 \\
\hline & C-Model 2 & 1677 & 182 & 861 \\
\hline Supplier2 & C-Model 1 & 1504 & 166 & 410 \\
\hline \multirow{2}{*}{ Supplier3 } & P-Model 1 & 1880 & 144 & 679 \\
\hline & C-Model 1 & 1054 & 198 & 410 \\
\hline \multirow{3}{*}{ Supplier4 } & P-Model 1 & 936 & 193 & 576 \\
\hline & P-Model 2 & 1915 & 197 & 679 \\
\hline & C-Model 2 & 1311 & 198 & 554 \\
\hline \multirow{3}{*}{ Supplier5 } & P-Model 1 & 1667 & 193 & 652 \\
\hline & P-Model 2 & 1915 & 197 & 679 \\
\hline & C-Model 2 & 1197 & 196 & 951 \\
\hline
\end{tabular}

$\mathrm{P}^{*}$ : Periodic review model, $\mathrm{C}^{*}$ : Continuous review model.

Different Suppliers are selected to satisfy DCs replenishment orders by continuous and periodic review models as given in Table II. When TSCC and lost sales cost for DCs are considered, C-Model 1 is significantly better than other models as seen in Fig. 2.
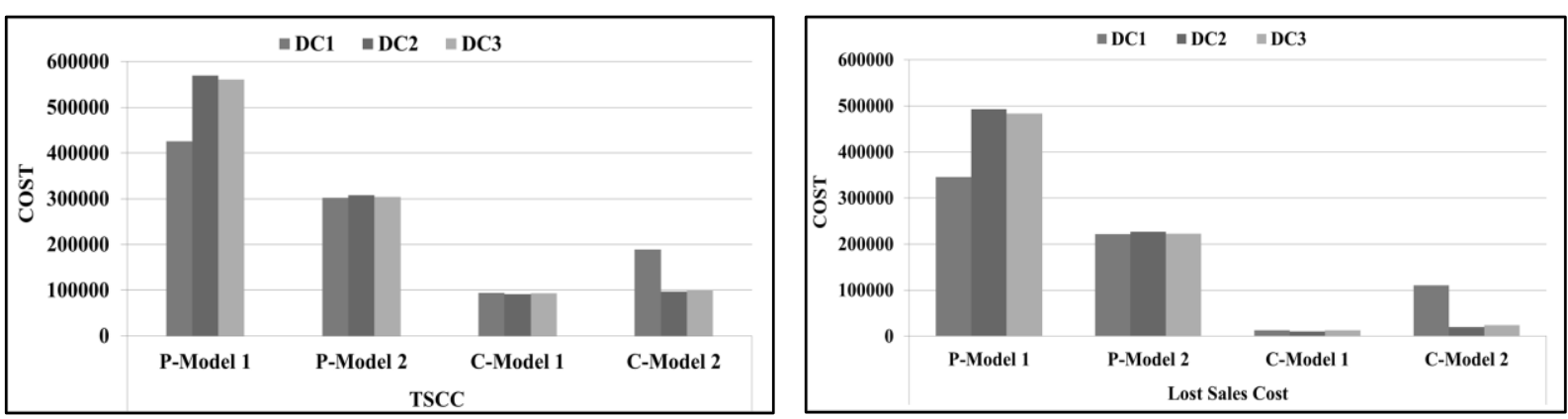

Figure 2: The comparison of TSCC and lost sales cost for DCs.

C-Model 1 can be used to increase responsiveness and customer satisfaction in today's competitive environment. In addition to the analysis of TSCC and lost sales cost, a comprehensive analysis including order based analysis per each period (number of totally lost order (NTLO) and number of partially lost order (NPLO)), probability based analysis (order met probability per period $(P 1)$ and overall order met probability $(P 2)$ ), and quantity based analysis per each period (totally met order quantity $(T M O Q)$, totally lost order quantity $(T L O Q)$, and partially lost order quantity $(P L O Q))$ are taken into consideration. 
For DC1 it is observed that the $T L O Q$ value of C-Model 1 is equal to zero on average while its value is 276, 164, and 50 on average for P-Model 1, P-Model 2, and C-Model 2, respectively. Also, $P L O Q$ and $T M O Q$ values on average for $\mathrm{DC} 1$ are given in Fig. 3.
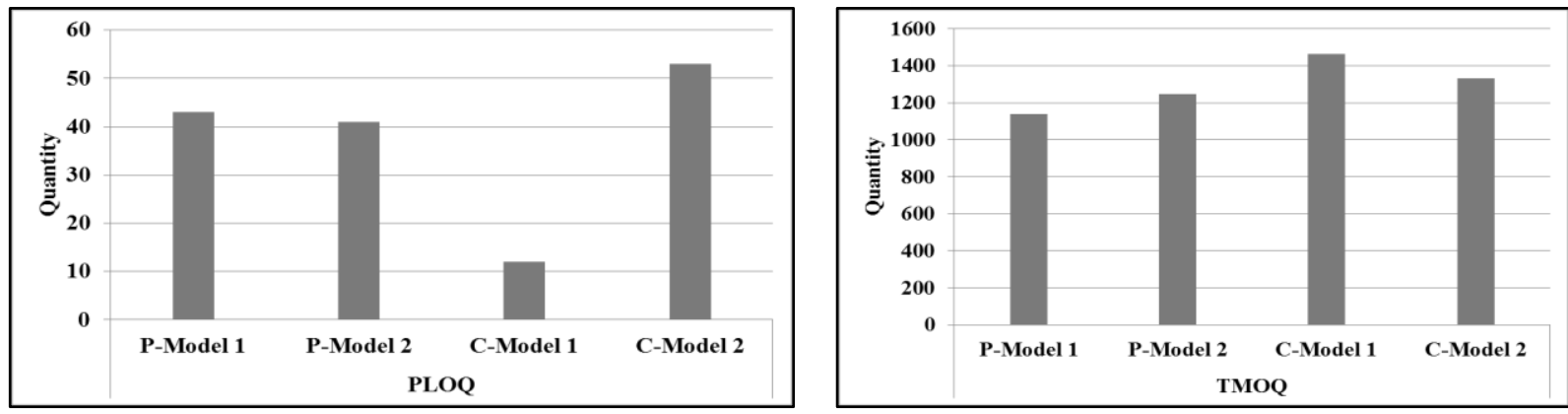

Figure 3: The value of $P L O Q$ and $T M O Q$ for DC1.

According to the order based analysis, the value of $N P L O$ for DC1 with all review models considered is found to be 1 order on average. $N T L O$ values for DC1 are generally zero in continuous review models while in periodic review models $N T L O$ is observed to be 6 orders on average.

For both Suppliers and DCs, $P 1$ specifies the percentage of meeting incoming orders at one month period and is calculated by using Eq. (7). Also, $P 2$ is defined as the percentage of meeting incoming orders over $n$ periods and is calculated by using Eq. (8) for comparison purposes.

$$
\begin{gathered}
P 1=\int_{n-1}^{n} \min \left(1, \frac{\text { Current Inventory Level }}{\text { Incoming Order Quantity }}\right) d t \\
P 2=\int_{0}^{n} \min \left(1, \frac{\text { Current Inventory Level }}{\text { Incoming Order Quantity }}\right) d t
\end{gathered}
$$

Note that if the values of $P 1$ and $P 2$ are close to 1 , DCs/Suppliers have the potential to satisfy all incoming demands over periods. According to the probability based analysis, $P 1$ values with C-Model 1 for DC1 improve at an average of $26 \%, 15 \%$, and $7 \%$ with respect to P-Model 1, P-Model 2, and C-Model 2, respectively. P2 values with C-Model 1 for DC1 improve at an average of $21 \%, 12 \%$, and $6 \%$ with respect to P-Model 1, P-Model 2, and CModel 2, respectively.

For DC2 it is observed that the $T L O Q$ value of C-Model 1 is equal to zero on average while its value is 410, 168, and 1 on average for P-Model 1, P-Model 2, and C-Model 2, respectively. Also, average values of $P L O Q$ and $T M O Q$ for DC2 are given in Fig. 4.
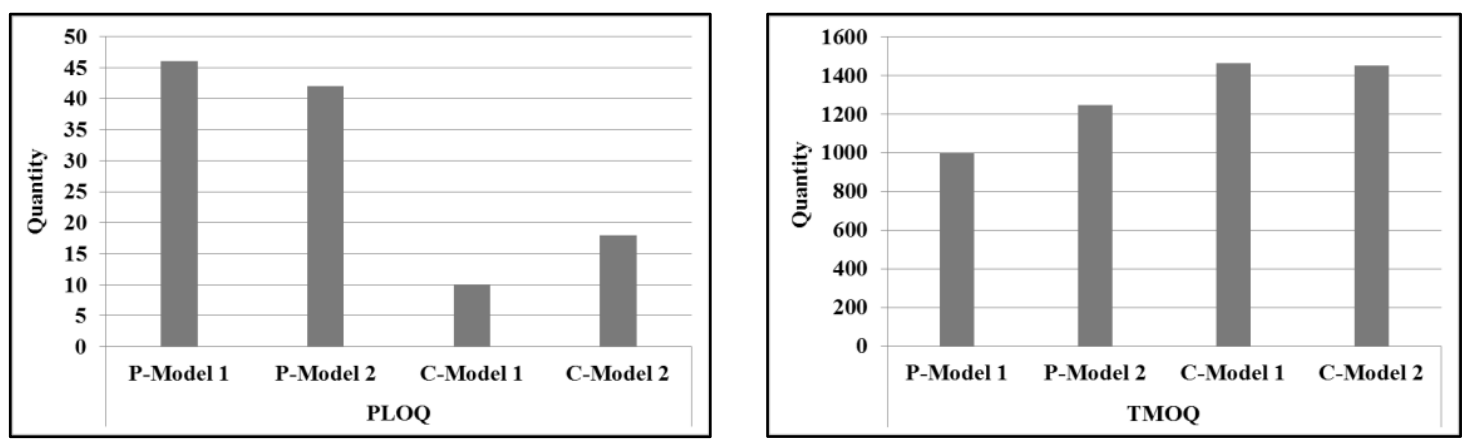

Figure 4: The value of $P L O Q$ and $T M O Q$ for DC2.

According to the order based analysis, the value of $N P L O$ for DC2 is 1 order on average in continuous review models while on average its value is 2 orders in periodic review models. 
$N T L O$ values for DC2 are zero in continuous review models while in P-Model 1 and P-Model $2 N T L O$ is observed to be 9 orders and 3 orders on average, respectively.

According to the probability based analysis, $P 1$ values with C-Model 1 for DC2 improve at an average of $43 \%, 16 \%$, and $1 \%$ with respect to P-Model 1, P-Model 2, and C-Model 2, respectively. $P 2$ values with C-Model 1 for DC2 improve at an average of $32 \%, 13 \%$, and $1 \%$ with respect to P-Model 1, P-Model 2, and C-Model 2, respectively.

For DC3 it is observed that the $T L O Q$ value of C-Model 1 is equal to zero on average while its value is 402, 162, and 1 on average for P-Model 1, P-Model 2, and C-Model 2, respectively. Also, PLOQ and TMOQ values on average for DC3 are given in Fig. 5. According to the order based analysis, the value of $N P L O$ for DC3 is 1 order on average in continuous review models while on average its value is 2 orders in periodic review models. $N T L O$ values for DC3 are zero in continuous review models while in P-Model 1 and P-Model $2 N T L O$ is observed to be 8 orders, and 3 orders on average, respectively. According to the probability based analysis, $P 1$ values with C-Model 1 for DC 3 improve at an average of $41 \%$, $15 \%$, and $1 \%$ with respect to P-Model 1, P-Model 2, and C-Model 2, respectively. P2 values with C-Model 1 for DC3 improve at an average of $30 \%, 12 \%$, and $1 \%$ with respect to PModel 1, P-Model 2, and C-Model 2, respectively.
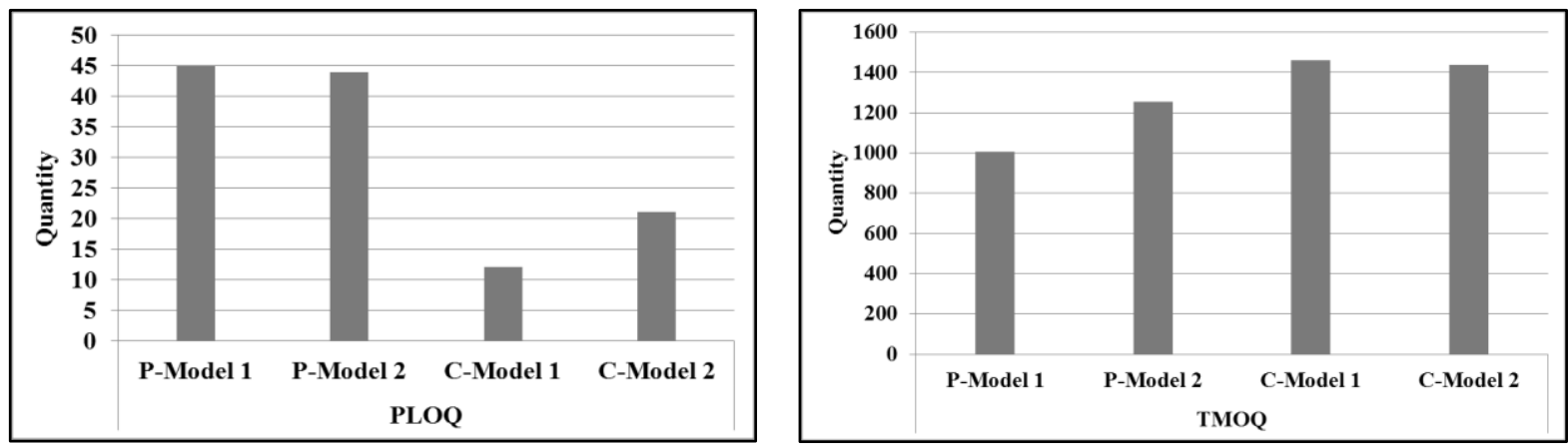

Figure 5: The value of $P L O Q$ and $T M O Q$ for DC3.

In DCs, if company has to use the periodic review model, P-Model 2 is better than PModel 1.The percentage of improvement depending on TSCC, lost sales cost, probability based analysis, quantity based analysis per each period, and order based analysis per each period is given in Fig. 6. The value of NPLO is same for both periodic review models. Although NTLO value at DC1 is same for both models, the difference between models is five on average for DC2 and DC3.

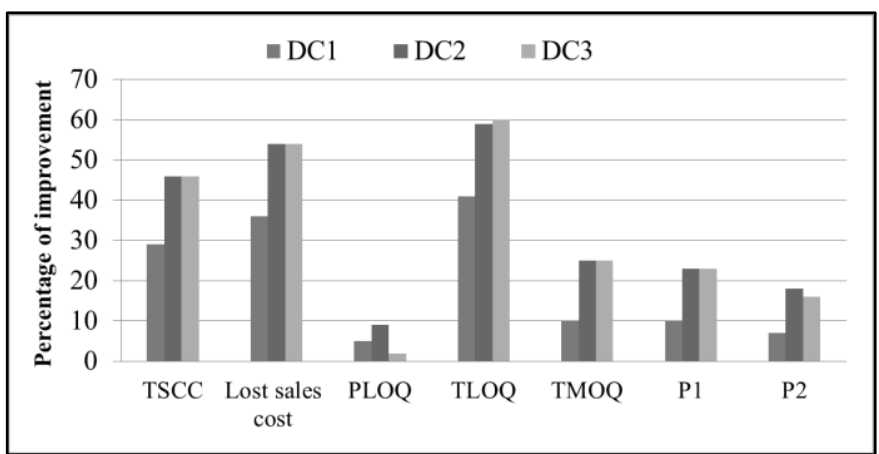

Figure 6: Percentage of improvement with P-Model 2 in DCs with respect to P-Model 1.

The magnitude of the decrease of the lost sales cost is not as high with the DCs as seen in Fig. 7 where TSCC for each Supplier is also given. According to the quantity based analysis, $P L O Q$ is zero for C-Model 1 and is 39 units on average for C-Model 2 while its value is 2 
units on average in P-Model 2 for Supplier1. TLOQ is zero in continuous review models while its value is 42 units on average for P-Model 2.
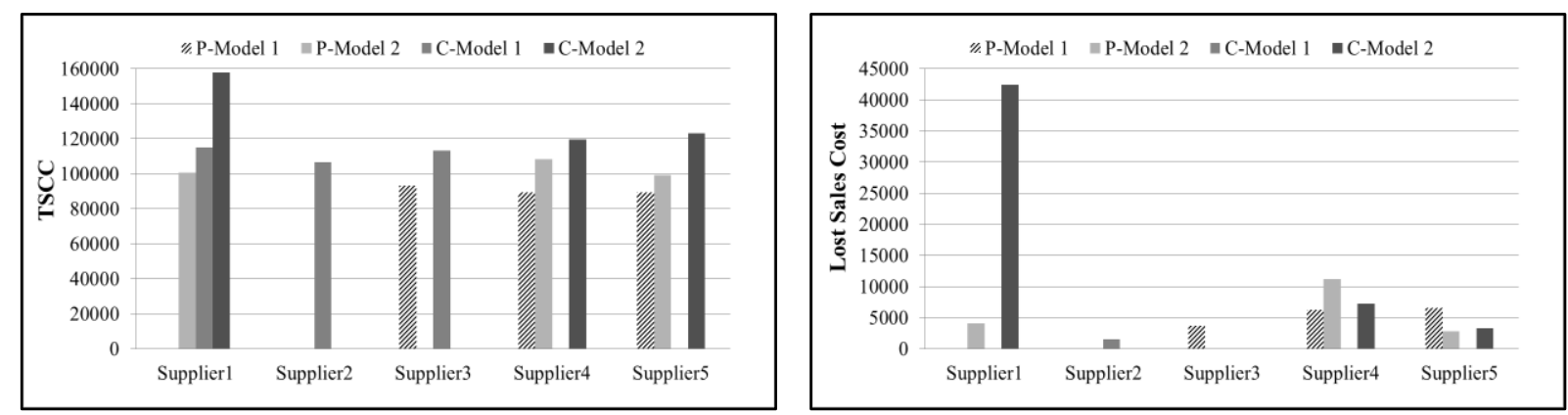

Figure 7: The comparison of TSCC and lost sales cost for Suppliers.

The average value of $P 1, P 2$, and $T M O Q$ for Supplier1 is given in Fig. 8.
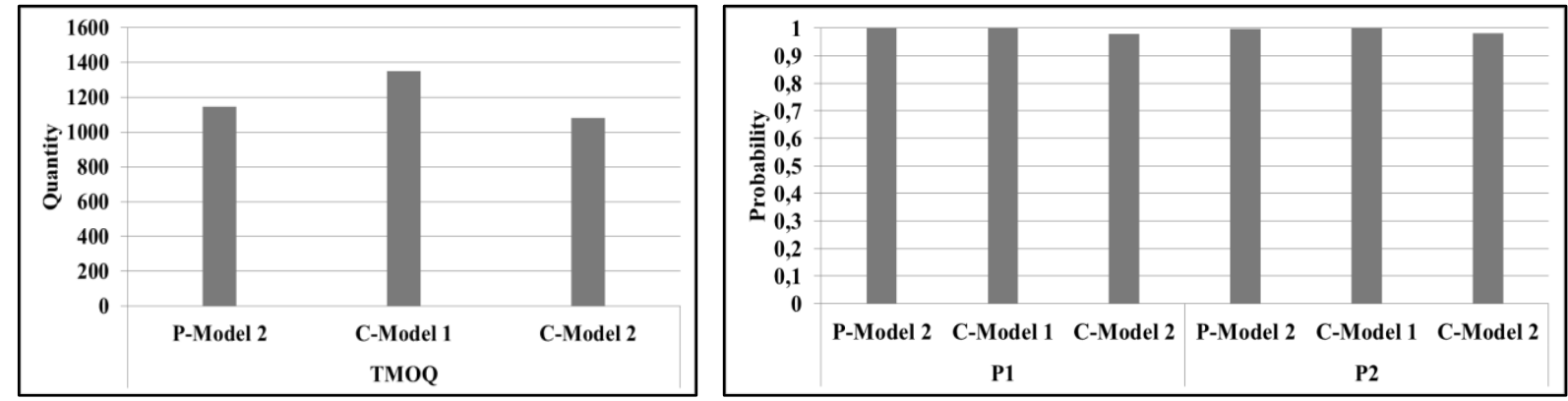

Figure 8: The analysis of Supplier1 for each model.

Note that Supplier2 is only used by C-Model 1 and therefore comparison is not available for this supply chain member. According to the order based analysis, NPLO value for Supplier3 is zero for C-Model 1 while its value is 1 order on average for P-Model 1. NTLO values are zero for both models for Supplier3. According to the quantity based analysis, $P L O Q$ is zero for C-Model 1 while its value is 3 units on average for P-Model 1. For Supplier3, TLOQ is zero for both models. The analysis of $T M O Q, P 1$ and $P 2$ values on average for Supplier3 is given in Fig. 9.
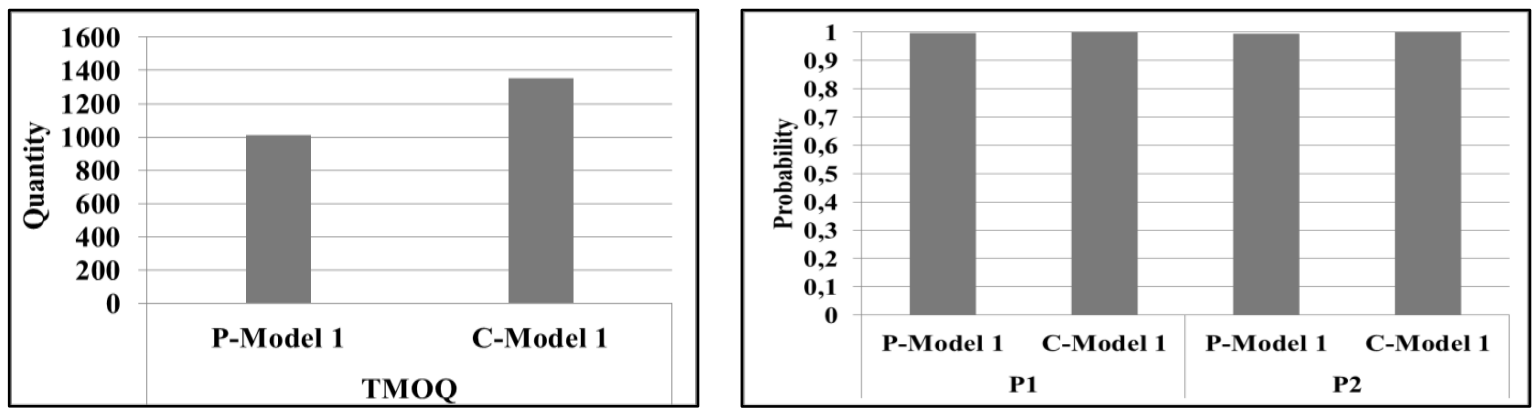

Figure 9: The analysis of Supplier3 for each model.

According to the order based analysis, NPLO for Supplier4 is 1 order on average for used models. NTLO is zero for P-Model 1 and C-Model 2 while its value is 1 order for P-Model 2. According to the quantity based analysis, $P L O Q$ is 6 units on average for used models. TLOQ is zero in P-Model 1 and C-Model 2 while its value is 5 units on average for P-Model 2. The analysis of $T M O Q, \mathrm{P} 1$ and $\mathrm{P} 2$ for Supplier4 values on average is given in Fig. 10. 

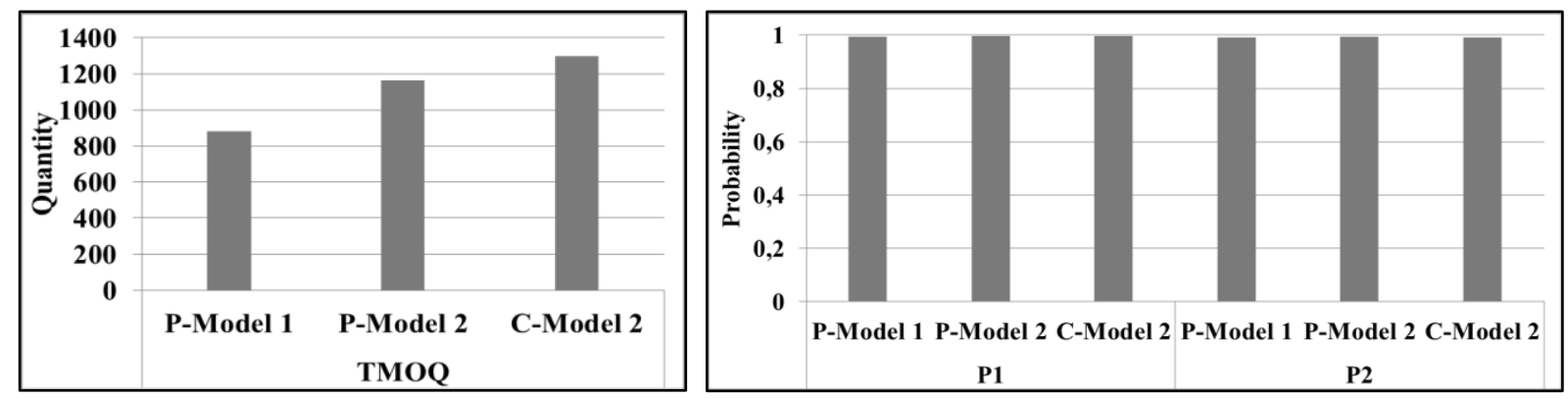

Figure 10: The analysis of Supplier4 for each model.

According to the order based analysis, NPLO for Supplier5 is 1 order on average for PModel 2 and C-Model 2 while its value is zero for P-Model 1. For Supplier5, NTLO is zero for used models. According to the quantity based analysis, $P L O Q$ is 3 units on average for PModel 2 and C-Model 2 while its value is zero for P-Model 1. TLOQ is zero for used models for Supplier5. The analysis of $T M O Q, P 1$ and $P 2$ values on average for Supplier5 is given in Fig. 11.
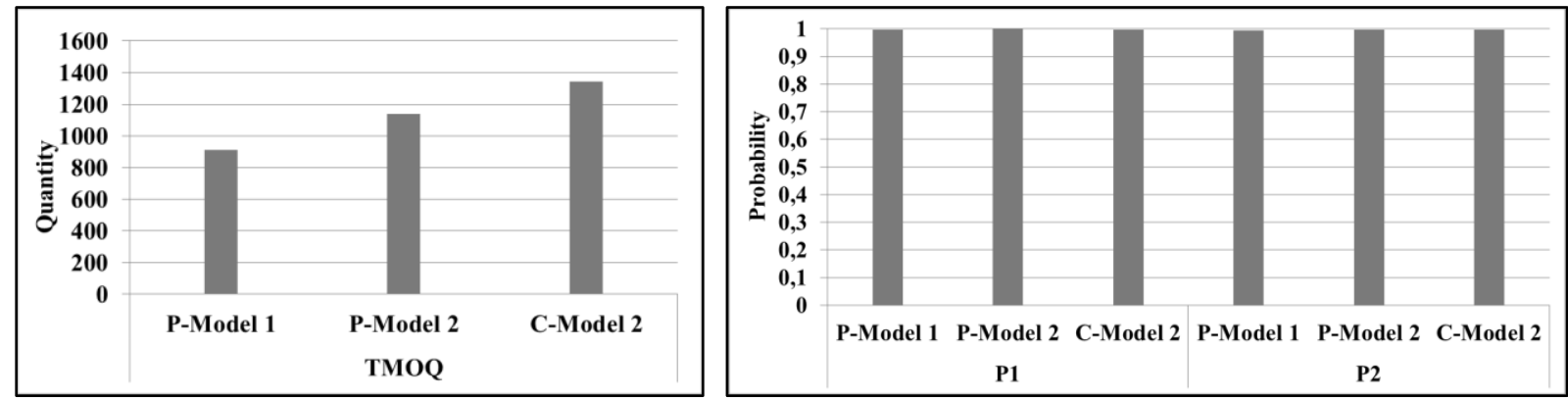

Figure 11: The analysis of Supplier5 for each model.

Each company is unique and includes many different inventory control systems. For example, the detailed analysis on continuous $(s, S)$ inventory control systems can be found in [23]. Defining which review model to use depends on the properties of the company. Therefore, extensive analysis of review models are made to provide the manager with more information about the optimal review model. Proposed continuous review $(s, S)$ policies and periodic review $(s, S)$ policies obtained in this study can provide a guideline on what companies need to do in order to increase their performance.

\section{CONCLUSION}

Understanding of the whole supply chain perfectly is needed to select an effective model because every company has different processes and different forms of strategies. Therefore, many different analysis including cost based analysis and customer satisfaction based analysis should be used to evaluate proposed models. The results of this study show that managers can increase company's competitiveness and responsiveness by using OvS models. The lost sales cost of review models can be improved at least $46 \%$ and at most $98 \%$ on average for DCs with C-Model 1. If company must use the periodic review model, the lost sales cost can be reduced at least $36 \%$ and at most $54 \%$ on average with P-Model 2 for DCs. The TSCC of PModel 1, P-Model 2 and C-Model 2 can be improved at an average of $66 \%, 50 \%$ and $22 \%$, respectively with C-Model 1. For periodic review models, the TSCC of P-Model 1 can also be improved at an average of $33 \%$ with P-Model 2.

This study is added to a practical knowledge of OvS based inventory management and compared review models to make companies closer towards achieving business excellence. 
To understand better the scope of review models and opportunities associated with inventory management, we give a detailed analysis of review models. The overall goal is to extract dynamics of the system considered and transform it into an understandable structure for managerial decision making. Inventory managers can easily determine the differences between supply chain members and then conduct further investigations to establish plausible explanations for differences.

Although OvS models have the ability to extract dynamics of the system considered, this study has some limitations. First, Poisson distribution is only used with a rate parameter of 50 . Proposed OvS models should be compared with different demand rates to determine how they affect whole supply chain. Second, review period is fixed in periodic $(s, S)$ models. At this point, GA can be used to optimize review period which may affect the OvS models. The other good direction for future research would be to consider other metaheuristic such as harmony search and particle swarm optimization to compare the performance of the proposed models. The paper shall also be of great value to researchers to extend their research avenues into this exiting area.

\section{REFERENCES}

[1] Kiesmüller, G. P.; de Kok, A. G.; Dabia, S. (2011). Single item inventory control under periodic review and a minimum order quantity, International Journal of Production Economics, Vol. 133, No. 1, 280-285, doi:10.1016/j.ijpe.2010.03.019

[2] Hollier, R. H.; Makj, K. L.; Lam, C. L. (1995). Continuous review (s, S) policies for inventory systems incorporating a cutoff transaction size, International Journal of Production Research, Vol. 33, No. 10, 2855-2865, doi:10.1080/00207549508904849

[3] Bashyam, S.; Fu, M. C. (1998). Optimization of (s, S) inventory systems with random lead times and a service level constraint, Management Science, Vol. 44, No. 12 - Part-2, S243-S256, doi: $10.1287 / \mathrm{mnsc} .44 .12 . \mathrm{s} 243$

[4] Moors, J. J. A.; Strijbosch, L. W. G. (2002). Exact fill rates for $(R, s, S)$ inventory control with gamma distributed demand, Journal of the Operational Research Society, Vol. 53, No. 11, 12681274, doi:10.1057/palgrave.jors.2601441

[5] Hu, J.; Watson, E.; Schneider, H. (2005). Approximate solutions for multi-location inventory systems with transshipments, International Journal of Production Economics, Vol. 97, No. 1, 3143, doi:10.1016/j.ijpe.2004.05.003

[6] Tlili, M.; Moalla, M.; Campagne, J.-P. (2012). The trans-shipment problem in a two-echelon, multi-location inventory system with lost sales, International Journal of Production Research, Vol. 50, No. 13, 3547-3559, doi:10.1080/00207543.2012.671590

[7] Cabrera, G.; Miranda, P. A.; Cabrera, E.; Soto, R.; Crawford, B.; Rubio, J. M.; Paredes, F. (2013). Solving a novel inventory location model with stochastic constraints and $(R, S, S)$ inventory control policy, Mathematical Problems in Engineering, Paper ID 670528, 12 pages, doi: $10.1155 / 2013 / 670528$

[8] Nasr, W. W.; Maddah, B. (2015). Continuous $(s, S)$ policy with MMPP correlated demand, European Journal of Operational Research, Vol. 246, No. 3, 874-885, doi:10.1016/ j.ejor.2015.05.029

[9] Göçken, M.; Dosdoğru, A. T.; Boru, A.; Geyik, F. (2015). (R, s, S) inventory control policy and supplier selection in a two-echelon supply chain: An optimization via simulation approach, Proceedings of the 2015 Winter Simulation Conference (WSC), 2057-2067, doi:10.1109/ WSC.2015.7408320

[10] Levi, R.; Janakiraman, G.; Nagarajan, M. (2008). A 2-approximation algorithm for stochastic inventory control models with lost sales, Mathematics of Operations Research, Vol. 33, No. 2, 351-374, doi:10.1287/moor.1070.0285

[11] Sahin, I. (1982). On the objective function behavior in $(s, S)$ inventory models, Operations Research, Vol. 30, No. 4, 709-724, doi:10.1287/opre.30.4.709 
[12] Ding, H.; Benyoucef, L.; Xie, X. (2005). A simulation optimization methodology for supplier selection problem, International Journal of Computer Integrated Manufacturing, Vol. 18, No. 23, 210-224, doi:10.1080/0951192052000288161

[13] Annadurai, K.; Uthayakumar, R. (2010). Reducing lost-sales rate in $(T, R, L)$ inventory model with controllable lead time, Applied Mathematical Modelling, Vol. 34, No. 11, 3465-3477, doi:10.1016/j.apm.2010.02.035

[14] Bijvank, M.; Johansen, S. G. (2012). Periodic review lost-sales inventory models with compound Poisson demand and constant lead times of any length, European Journal of Operational Research, Vol. 220, No. 1, 106-114, doi:10.1016/j.ejor.2012.01.041

[15] Fang, D. J.; Li, C. (2014). Simulation-based hybrid approach to robust multi-echelon inventory policies for complex distribution networks, International Journal of Simulation Modelling, Vol. 13, No. 3, 377-387, doi:10.2507/ijsimm13(3)co15

[16] Smew, W.; Young, P.; Geraghty, J. (2013). Supply chain analysis using simulation, Gaussian process modelling and optimisation, International Journal of Simulation Modelling, Vol. 12, No. 3, 178-189, doi:10.2507/ijsimm12(3)4.239

[17] Xu, J.; Huang, E.; Chen, C.-H.; Lee, L. H. (2015). Simulation optimization: a review and exploration in the new era of cloud computing and big data, Asia-Pacific Journal of Operational Research, Vol. 32, No. 3, Paper ID 1550019, 34 pages, doi:10.1142/s0217595915500190

[18] Ólafsson, S. (2006). Metaheuristics (Ch. 21), Handbooks in Operations Research and Management Science, Vol. 13, 633-654, doi:10.1016/S0927-0507(06)13021-2

[19] Wu, G.-D.; Tang, D.-Z. (2015). Inter-organizational cooperative innovation of project-based supply chains under consideration of monitoring signals, International Journal of Simulation Modelling, Vol. 14, No. 3, 539-550, doi:10.2507/ijsimm14(3)co14

[20] Al-Hawari, T.; Ahmed, A.; Khrais, S.; Mumani, A. (2013). Impact of assignment, inventory policies and demand patterns on supply chain performance, International Journal of Simulation Modelling, Vol. 12, No. 3, 164-177, doi:10.2507/ijsimm12(3)3.235

[21] Costantino, F.; Di Gravio, G.; Shaban, A.; Tronci, M. (2014). Inventory control system based on control charts to improve supply chain performances, International Journal of Simulation Modelling, Vol. 13, No. 3, 263-275, doi:10.2507/ijsimm13(3)1.263

[22] Kelton, W. D.; Smith, J. S.; Sturrock, D. T.; Göçken, M.; Dosdoğru, A. T. (2015). Simio \& Simulation: Modeling, Analysis, Applications: Turkish Translation, $3^{\text {rd }}$ edition, Simio LLC

[23] Göçken, M.; Dosdoğru, A. T.; Boru, A.; Geyik, F. (2017). Characterizing continuous (s, S) policy with supplier selection using Simulation Optimization, Simulation: Transactions of the Society for Modeling and Simulation International, Vol. 93, No. 5, 379-396, doi:10.1177/ $\underline{0037549716687044}$ 